\title{
FORUM
}

\section{Um etliche Ecken ged8}

\section{Gehirn-Jogging auf Basis der math.- und informatisch-orientierten Rechtschreibreform}

\section{Rolf Windenberg ${ }^{1}$}

Online publiziert: 17. März 2020

๑) Springer-Verlag GmbH Deutschland, ein Teil von Springer Nature 2020

Abb. 1 Kleine Hilfe zur Lösung der vierten Knobelaufgabe. (Quelle: [1])

\section{Regeln:}

1. Verwendung einfacher math. Symbole und von Zahlen

2. Aussprache von Großbuchstaben wie im Alphabet

3. Bei der informatisch-orientierten Reform: zusätzlich Verwendung programmiersprachlicher Symbole

Beispiel: „0 • 8“ steht für „Oma lacht“

\section{Knobelaufgaben:}

- Anfänger: E/he

- Spielerei mit Buchstaben: sLTne LMNT

- Fortgeschrittene: $\mathrm{KCn}+\mathrm{h}+\mathrm{e}$ vRsTN sich sLtN BsondRs gut

- Experten: Dr $\mathbf{h}+$ muss $\bullet \pi \pi$

- Genies: ((m1e) $\left.{ }^{8 u n g}\right)^{\text {würdN }}$

- Informatisch-orientiert: (2) 